Randomized Trial

\title{
Efficacy of Magnesium Sulfate Added to Local Anesthetic in a Transversus Abdominis Plane Block for Analgesia Following Total Abdominal Hysterectomy: A Randomized Trial
}

Kelany A Abd-Elsalam, MD', Khaled M. Fares, MD², Montaser A. Mohamed, MD², Mohamad F. Mohamad, MD², Ahmad M. Abd El-Rahman, MD², and Moaaz M. Tohamy, MSc²

\footnotetext{
From: ${ }^{1}$ Assiut University Hospital, Assiut, Egypt; ${ }^{2}$ South Egypt Cancer Institute, Assiut University, Assiut, Egypt

Address Correspondence: Ahmad M. Abd El-Rahman,

MD

South Egypt Cancer Institute, Assiut University Assiut, Egypt 71516 Email: ahmad23679@gmail.

com

Disclaimer: There was no external funding in the preparation of this manuscript.

Conflict of interest: Each

author certifies that he or

she, or a member of his or her immediate family, has no commercial association (i.e., consultancies, stock ownership, equity interest, patent/

licensing arrangements, etc.) that might pose a conflict of interest in connection with the submitted manuscript.

Manuscript received: 02-04-2017

Accepted for publication: 05-16-2017

Free full manuscript: www.painphysicianjournal.com
}

Background: Major abdominal surgeries are associated with severe pain, which can affect respiratory and cardiac functions if insufficiently treated; this increases postoperative morbidity.

Objective: We aim at evaluating the efficacy of magnesium sulfate as an adjuvant to local anesthetic in an ultrasound-guided transversus abdominis plane (TAP) block for postoperative analgesia in total abdominal hysterectomy.

Study Design: A prospective, randomized, double-blinded clinical trial.

Setting: An academic medical center.

Methods: This study is registered at https://clinicaltrials.gov (no.: NCT02930707). This randomized, double-blinded clinical trial included 60 women undergoing total abdominal hysterectomy that were divided into 2 groups (30 patients per group). Group I received a TAP block with $20 \mathrm{~mL}$ per side of $0.25 \%$ bupivacaine plus $2 \mathrm{~mL}$ magnesium sulphate 10\% (200 mg). Group II received a TAP block with $20 \mathrm{~mL}$ per side of $0.25 \%$ bupivacaine. Visual analog scale (VAS) scores, the time of the first analgesic request, total morphine consumption, and any side effects were assessed and recorded.

Results: The mean postoperative VAS score was significantly reduced in group I compared to group II in all of the time-points except after 10 hours. The mean time of the first request for rescue analgesia was significantly prolonged in group I (15.67 hrs.) compared to group II (7.33 hrs.) $(P<$ $0.001)$, and the mean total morphine consumption, over the first 24 hours postoperatively, was significantly lower in group I $(7.63 \pm 2.93 \mathrm{mg})$ than in group $\|(16.20 \pm 3.24 \mathrm{mg})(P<0.001)$. No significant difference in side effects was observed.

Limitations: Sample size.

Conclusion: The addition of $200 \mathrm{mg}$ of magnesium sulfate to bupivacaine in an ultrasound-guided TAP block significantly reduced postoperative opioid requirements, prolonged the duration of analgesia, and reduced the VAS score in patients who underwent abdominal hysterectomy, without significant side effects.

Key words: Magnesium sulfate, TAP block, postoperative pain, total abdominal hysterectomy

Pain Physician 2017; 20:641-647

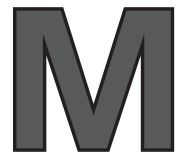

ajor abdominal surgeries are associated with severe abdominal pain, which if inadequately treated, can increase the incidence of postoperative morbidity and lead to a delayed recovery (1).

Opioid administration remains the mainstay of postoperative pain relief, but it can result in significant adverse effects including sedation, nausea, vomiting, urinary retention, respiratory depression, delayed recovery of colonic mobility, and prolonged postoperative ileus (2).

The transversus abdominis plane (TAP) block is 
a compartment block in which the local anesthetic is distributed deep to the fascia between the internal oblique muscle and the transversus abdominis muscle. It blocks almost all of the somatic nerves that pass through the abdominal structures that are cut during abdominal incision and are a cause of pain generation after surgery (3-5).

The TAP block was first described by Rafi (6) and the procedure was named by McDonnell and others $(3,5)$, while Hebbard (7) was the first to use sonography for this type of block. This method is a suitable substitute for epidural analgesia in abdominal surgeries that have a minimal visceral pain component to them. A TAP block reduces opioid consumption and its complications (nausea, vomiting, urinary retention, decrease in blood pressure, and so on) and does not have the side effects of a neuraxial block (decrease in blood pressure, motor block) $(8,9)$. The procedure is simple and easily executed, without any encroachment on the epidural space with effective analgesia, and it is very suitable in patients who are not candidates for epidural analgesia $(8,9)$.

Magnesium sulfate has been shown to have antinociceptive effects in animal and human models by blocking the $\mathrm{N}$-methyl-D-aspartate (NMDA) receptor and associated calcium channels, thus preventing central sensitization caused by peripheral nociceptive stimulation. In addition to their central location, recent studies identified peripheral NMDA receptors in the skin, muscles, and knee joints and found that they play a role in sensory transmission of noxious signals (10).

The addition of magnesium sulfate to local anesthetics for neuraxial anesthesia prolongs the duration of anesthesia and improves the quality of analgesia. However, there are few clinical studies assessing the addition of magnesium for peripheral nerve blocks (10).

The objective of this study was to detect the efficacy of magnesium sulfate as an adjuvant to local anesthetic in an ultrasound-guided TAP block in patients undergoing total abdominal hysterectomy. Our primary aim was to detect the reduction in total postoperative morphine consumption.

\section{Methods}

This randomized, double-blinded study was approved by the ethics committee of South Egypt Cancer Institute, Assiut University in Assiut, Egypt. This study is recorded at https://clinicaltrials.gov with identifier no. NCT02930707. After obtaining written informed consent, 60 women (ASA classification I-III, aged $\geq 18$ years, weight: $50-85 \mathrm{~kg}$ ) who were scheduled for total abdominal hysterectomy for the management of uterine and ovarian cancer were included in this study. Patients with a history of relevant drug allergies, coagulation disorders, opioid dependence, morbid obesity (body mass index more than $40 \mathrm{~kg} / \mathrm{m}^{2}$ ), sepsis, and those with psychiatric illnesses that would interfere with the perception and assessment of pain were excluded from the study. Preoperatively, the patients were taught how to evaluate their own pain intensity using the visual analog scale (VAS), scored from $0-10$ (where $0=$ no pain and $10=$ worst pain imaginable).

The patients were randomly assigned into 2 groups using an online research randomizer (www.randomizer. org), with 30 patients in each group:

Group I patients received an ultrasound-guided TAP block with $20 \mathrm{~mL}$ of $0.25 \%$ bupivacaine plus $2 \mathrm{~mL}$ of magnesium sulfate $10 \%$ ( $200 \mathrm{mg}$ ) on each side of the abdominal wall in the midaxillary line in the midpoint between the costal margin and the iliac crest.

Group II patients received an ultrasound-guided TAP block with $20 \mathrm{~mL}$ of $0.25 \%$ bupivacaine on each side of the abdominal wall in the midaxillary line in the midpoint between the costal margin and the iliac crest.

\section{Ultrasound-Guided TAP Block Technique}

The ultrasound-guided TAP block was performed before the induction of general anesthesia. Upon arrival at the operating room, the patients were placed in the supine position and an 18-gauge intravenous (IV) cannula was inserted for IV fluid and drug administration. Basic monitoring probes (electrocardiography, non-invasive blood pressure, oxygen saturation, and temperature) were applied, and their baseline vital signs were recorded. Lactated Ringer's solution $10 \mathrm{~mL} /$ $\mathrm{kg}$ was infused intravenously over 10 minutes before the initiation of the TAP block.

The study drugs were prepared in the hospital pharmacy, and the attending anesthetist was blinded to it. The TAP block was performed with the use of ultrasound, under complete aseptic technique. A broadband linear array probe was used with an imaging depth of $4-6 \mathrm{~cm}$. The ultrasound probe was placed transversely to the abdomen (horizontal plane) in the midaxillary line between the costal margin and the iliac crest. Three muscle layers are clearly seen in the image. The needle (22-gauge x $80 \mathrm{~mm}$ SonoPlex stim cannula, Pajunk $^{\circledR}$, Geisingen, Germany) was inserted in a sagittal plane approximately $3-4 \mathrm{~cm}$ medial to the ultrasound probe. The point of needle insertion was closer to the 
probe. For optimal imaging of the needle, it was held parallel to the long axis of the probe (in-line view). The needle tip was directed into the plane below the internal oblique and above the transversus abdominis muscle. A small volume of local anesthetic $(2 \mathrm{~mL})$ was seen to open the plane between the 2 muscles and was followed by insertion of the full dose of local anesthetic. If the $2 \mathrm{~mL}$ dose appears to be within the muscle rather than between them, then needle adjustment was required. The local anesthetic injectate appeared hypoechoic (black compared to the muscle layers) on ultrasound image.

The TAP block was performed with the use of ultrasound under complete aseptic technique. A broadband linear array probe was used with an imaging depth of $4-6 \mathrm{~cm}$ using a 22-gauge $\times 80 \mathrm{~mm}$ SonoPlex stim cannula (Pajunk ${ }^{\oplus}$, Geisingen, Germany). Twenty minutes after the TAP block, the extent of sensory blockade was evaluated by using the pin prick test $(0=$ no block, 1 $=$ hyposthesia, and $2=$ anesthesia) by another blinded attending anesthetist. Any patients with a failed block were excluded from both of the groups.

\section{Anesthetic Technique}

The anesthetic technique was standardized in the 2 groups. No preoperative analgesics were given. After a successful TAP block, general anesthesia was induced intravenously (propofol $1-2 \mathrm{mg} / \mathrm{kg}$, lidocaine $1.5 \mathrm{mg} /$ $\mathrm{kg}$ ) and fentanyl $1 \mu \mathrm{g} / \mathrm{kg}$. Endotracheal intubation was facilitated by neuromuscular blockade with cisatracurium $0.3 \mathrm{mg} / \mathrm{kg}$. Anesthesia and muscle relaxation were maintained with isoflurane in an air/oxygen mixture and cisatracurium $0.15 \mathrm{mg} / \mathrm{kg}$. The patients were mechanically ventilated in parameters that maintained the end-tidal $\mathrm{CO}_{2}\left(\mathrm{ETCO}_{2}\right)$ between 33 and $36 \mathrm{mmHg}$. The patients' heart rate, oxygen saturation, $\mathrm{ETCO}_{2^{\prime}}$ and systolic and diastolic blood pressures were measured and recorded. Hypotension was defined as a $15 \%$ decrease in systolic blood pressure from the base line, bradycardia as a heart rate slower than 50 beats per minute, and hypoxia as an oxygen saturation less than $90 \%$. Hypotension was treated with intravenous boluses of ephedrine $0.1 \mathrm{mg} / \mathrm{kg}$, repeated as required. Bradycardia was treated with intravenous atropine $0.01 \mathrm{mg} / \mathrm{kg}$.

At the end of surgery, muscle relaxation was reversed by neostigmine $50 \mu \mathrm{g} / \mathrm{kg}$ and atropine $10 \mu \mathrm{g} /$ $\mathrm{kg}$. The patients were extubated and transferred to the post-anesthesia care unit (PACU), where they were monitored for vital signs (heart rate, non-invasive blood pressure, respiratory rate, and $\mathrm{O}_{2}$ saturation) imme- diately postoperatively and at 2, 4, 6, 12, 18, and 24 hours postoperatively. A blinded observer collected the postoperative data.

The severity of pain and the presence of nausea, vomiting, and respiratory depression were assessed postoperatively at $1,2,4,6,8,10,12$, and 24 hours. The severity of pain was assessed using a $10 \mathrm{~cm}$ VAS $(0=$ no pain and $10=$ worst imaginable pain). If a patient's VAS score was $\geq 3$, morphine was administered intravenously by a dose of $0.05 \mathrm{mg} / \mathrm{kg}$ at 15 minute intervals until complete pain relief was achieved. Morphine administration was ceased when the VAS score was < 3 on assessment or when over-sedation or respiratory depression occurred (a respiratory rate of $<10 \mathrm{bpm}$ ). Rescue antiemetic was given in the form of metoclopramide $10 \mathrm{mg}$ IV when patients complained of nausea or vomiting. Our primary outcome measure was total morphine consumption in the first 24 hours postoperatively; our secondary outcome measures were the postoperative VAS scores, the time of the first request of rescue analgesia (calculated from the time of the TAP block application), and the incidence of side effects.

\section{Statistical Analysis}

Using clinical data from similar studies, it was postulated that in order to detect the difference in total postoperative morphine consumption, with an expected background standard deviation of one, a type I error of less than 0.05 , a power of $90 \%$, and a sample size of 27 patients in each group would be sufficient. We recruited 30 patients in each group to compensate for drop-outs and to account for random errors.

Data entry and analysis were done using SPSS Version 19.0 (IBM Corporation, Armonk, NY). Data were presented as number, percentage, and mean \pm standard deviation. A chi-square test was used to compare qualitative variables. A Mann-Whitney test was used to compare quantitative variables in the studied groups. A Wilcoxon signed rank test was done to compare each 2 time-points in the same group. The $P$-value was considered statistically significant when $P<0.05$.

\section{Results}

Sixty women, scheduled for total abdominal hysterectomy for the management of uterine and ovarian cancer, were included in this study. Our results regarding the patient demographic (age, weight, and height) and operative (duration of surgery and anesthesia) data showed an insignificant difference between the 2 groups (Tables 1 and 2, respectively). 
Considering the hemodynamics, the mean blood pressure was significantly lower in group I than in group II after 1 and 2 hours intraoperatively $(P<0.05)$ and at 8,10 , and 12 hours postoperatively $(P<0.00,0.029, \& 0.000$ respectively) (Fig. 1 and 2$)$.

The intraoperative heart rate was significantly lower in group I than in group II at 1,2 , and 4 hours $(P<0.05)$ and all over the time-points in the postoperative period $(P<0.01)$.

There were insignificant differences between both of the groups regarding the postoperative $\mathrm{O}_{2}$ saturation and respiratory rate at different time-points.

Table 1. Demographic data of the studied groups (mean $\pm S D$ ).

\begin{tabular}{|l|c|c|c||}
\hline & $\begin{array}{c}\text { Group I } \\
(\mathbf{n}=\mathbf{3 0})\end{array}$ & $\begin{array}{c}\text { Group II } \\
(\mathbf{n}=\mathbf{3 0})\end{array}$ & \multirow{2}{*}{-value } \\
\cline { 1 - 3 } Age (years) & $47.97 \pm 6.33$ & $48.67 \pm 10.01$ & \multirow{2}{*}{ NS } \\
\cline { 1 - 3 } Range & $40-60$ & $29-60$ & \multirow{2}{*}{ NS } \\
\cline { 1 - 3 } Weight $(\mathrm{kg})$ & $70.50 \pm 7.35$ & $72.83 \pm 6.11$ & \multirow{2}{*}{ NS } \\
\cline { 1 - 3 } Range & $60-85$ & $60-80$ & \\
\hline Height $(\mathrm{cm})$ & $156.80 \pm 4.16$ & $150-33 \pm 4.51$ & \\
\cline { 1 - 3 } Range & $150-165$ & & \\
\hline
\end{tabular}

Table 2. The durations of surgery and anesthesia (mean $\pm S D$ ).

\begin{tabular}{||l|c|c|c|}
\hline & $\begin{array}{c}\text { Group I } \\
(\mathbf{n}=\mathbf{3 0})\end{array}$ & $\begin{array}{c}\text { Group II } \\
(\mathbf{n}=\mathbf{3 0})\end{array}$ & \multirow{2}{*}{-value } \\
\cline { 1 - 3 } Duration of Surgery (hours) & $4.27 \pm 0.78$ & $4.47 \pm 0.73$ & \multirow{2}{*}{ NS } \\
\cline { 1 - 3 } Range & $3-6$ & $3-6$ & \\
\cline { 1 - 3 } Duration of Anesthesia (hours) & $5.27 \pm 0.78$ & $5.47 \pm 0.73$ & \multirow{2}{*}{ NS } \\
\cline { 1 - 3 } Range & $4-7$ & $4-7$ & \\
\hline
\end{tabular}

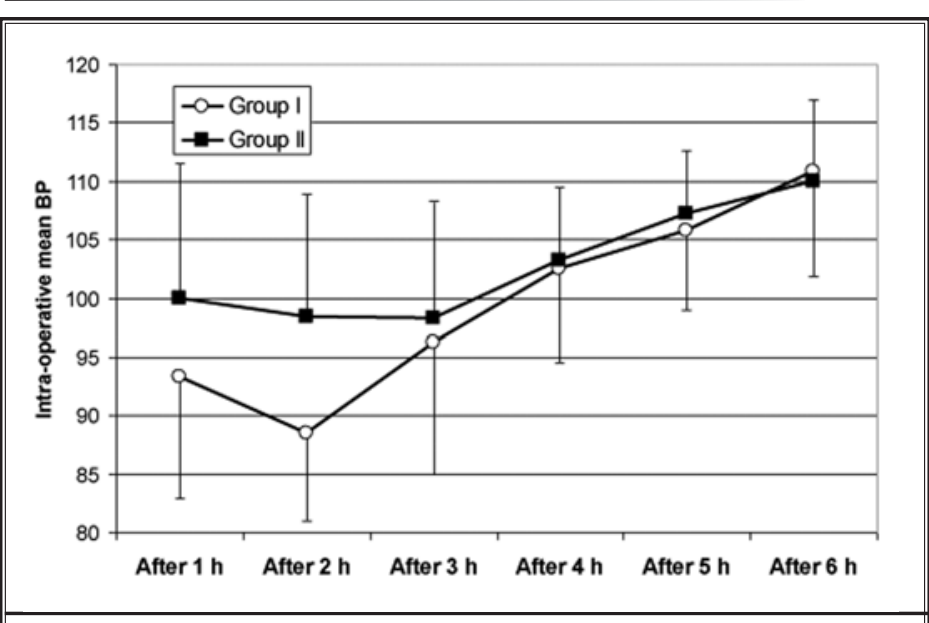

Fig. 1. Changes in the intraoperative mean blood pressure at 1, 2, 3, 4, 5, and 6 hours postoperatively.

Group I: TAP bupivacain + magnesium.

Group II: TAP bupivacain.
The mean postoperative VAS score was significantly lower in group I than in group Il at all of the time-points until after 8 hours, where there was an insignificant difference in between both groups; at 10 and 12 hours there was a significantly lower VAS score in group II compared to group I, and at 24 hours, the VAS scores were significantly lower in group I than in group II. Also, there were significant differences regarding the VAS scores between each 2 consecutive times in each group separately $(P<0.05)$ (Fig. 3).

The mean time of the first request for rescue analgesia calculated from the time of the TAP block application was significantly prolonged in group I patients than in group II patients (15.67 \pm 6.04 hours, and $6.33 \pm 0.96$ hours, respectively) $(P<0.001)$, and the mean total morphine consumption was significantly reduced in group I than in group II (7.63 \pm $2.93 \mathrm{mg}$ and $16.20 \pm 3.24 \mathrm{mg}$, respectively) $(P$ $<0.001$ ) (Table 3). Regarding side effects, nausea and vomiting occurred more frequently in group II compared to group I ( 7 and 5 patients, respectively, in group II compared to 3 and 3 patients, respectively, in group I), however this difference was not statistically significant $(P>$ 0.05) (Table 4).

\section{Discussion}

In the current study, the addition of $2 \mathrm{~mL}$ of magnesium sulphate $10 \%(200 \mathrm{mg})$ to local anesthetic given in an ultrasound-guided TAP block reduced postoperative opioid consumption, prolonged the duration of postoperative analgesia, and reduced postoperative pain scores in patients undergoing total abdominal hysterectomy under general anesthesia, without significant side effects.

Magnesium is a physiological calcium channel blocker and noncompetitive antagonist of N-methyl-D-aspartate (NMDA) receptors (11). It has been used with a local anesthetic solution in different regional anesthesia techniques to decrease the onset time of the block and to increase the quality and duration of anesthesia (10,12-15,).

The analgesic properties of magnesium on peripheral nerves can be explained by the surface charge theory. Akutagawa et al (16) 
showed that modulation of the external magnesium concentration bathing a nerve bundle resulted in the enhancement of the nerve blockade due to local anesthetics. Another possible mechanism for the analgesic action of magnesium is the voltage-dependent antagonism of NMDA receptors, which play a well-defined role in modulating pain and a number of inflammatory responses, leading to the prevention of central sensitization from peripheral nociceptive stimulation and a decrease in acute pain after tissue injury $(16,17)$.

In concordance with that finding, Gunduz et al (10) found a prolongation of sensory and motor block in axillary nerve block without any side effects when 150 mg magnesium was added to prilocaine. However, they did not evaluate the effect of magnesium sulfate on the intensity of postoperative pain, the duration of analgesia, and the consumption of postoperative analgesics.

Lee et al (18) compared magnesium sulfate at a dose of $200 \mathrm{mg}$ ( $2 \mathrm{~mL}$ of $10 \%$ solution magnesium sulfate) to normal saline when added to $0.5 \%$ bupivacaine with epinephrine in an interscalene nerve block for arthroscopic rotator cuff repair; they found a statistically significant prolongation of analgesia in the magnesium group than in the saline group $(664 \pm 188$ minutes vs. $553 \pm 155$ minutes, respectively).

Bondok et al (19) studied the effect of intraarticular magnesium in knee arthroscopy and showed that magnesium in a dose of $10 \mathrm{~mL}$ of magnesium sulphate $\left(\mathrm{MgSO}_{4}\right)$ at a concentration of $50 \mathrm{mg} / \mathrm{mL}$ resulted in a significant decrease in the postoperative VAS score in the first 24 hours, in addition to a significant decrease in the dose of postoperative rescue analgesia with a longer delay in the need for that analgesia, concluding that intraarticular magnesium can be a useful alternative for postoperative analgesia.

Furthermore, Elshama et al (20) assessed the potential analgesic effect of $5 \mathrm{~mL}$ of magnesium sulfate $10 \%$ solution (500 mg) when added to local anesthetic bupivacaine during a femoral nerve block. They concluded that it provided a profound prolongation
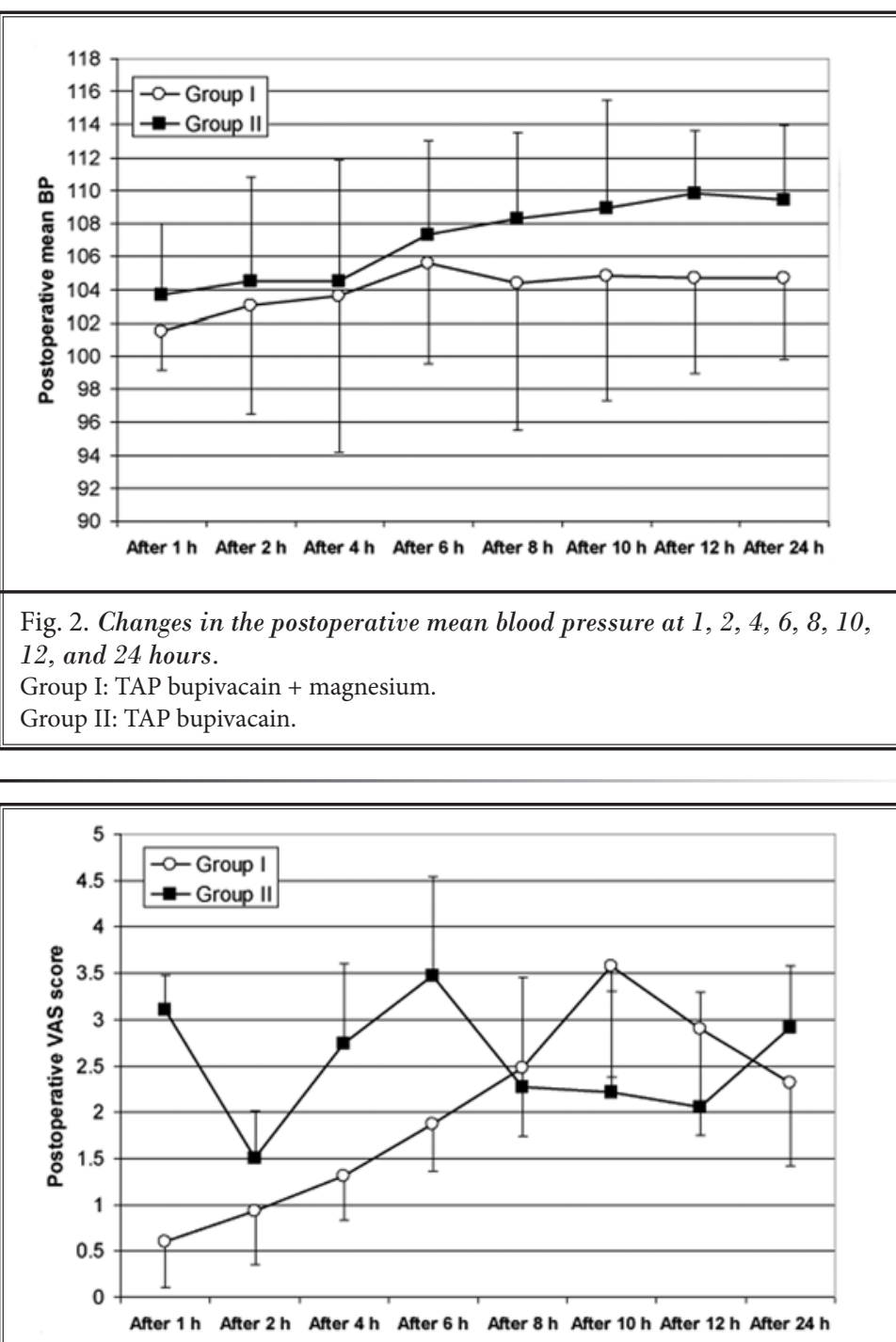

Fig. 3. Changes in the postoperative VAS score at 1, 2, 4, 6, 8, 10, 12, and 24 hours.

Group I: TAP bupivacain + magnesium.

Group II: TAP bupivacain.

of the block, in addition to a significant decrease in postoperative pain scores and the total dose of rescue analgesia.

Kashefi et al (21) studied the effect of adding magnesium to lidocaine during intravenous regional anesthesia and found that magnesium sulfate enhances the quality of anesthesia and analgesia during regional intravenous anesthesia, without causing side effects.

Recently, Rana and colleagues (22) investigated the analgesic effects of adding magnesium sulfate $(150 \mathrm{mg}$ ) to bupivacaine in an ultrasound-guided TAP block in patients who underwent total abdominal hysterectomy under a subarachnoid block and 
Pain Physician: November/December 2017: 20: 641-647

Table 3. The time of the first request for analgesia and the total analgesic consumption (mean $\pm S D$ ).

\begin{tabular}{|c|c|c|c|}
\hline & $\begin{array}{c}\text { Group I } \\
(\mathrm{n}=\mathbf{3 0})\end{array}$ & $\begin{array}{l}\text { Group II } \\
(\mathbf{n}=\mathbf{3 0})\end{array}$ & $P$-value \\
\hline Time of First Request for Analgesia (hour) & $15.67 \pm 6.04$ & $6.33 \pm 0.96$ & \multirow{2}{*}{$0.000^{*}$} \\
\hline Range & $10-24$ & $6-8$ & \\
\hline Total Analgesia Consumption (mg) & $7.63 \pm 2.93$ & $16.20 \pm 3.24$ & \multirow{2}{*}{$0.000^{*}$} \\
\hline Range & $5-14$ & $14-21$ & \\
\hline
\end{tabular}

Table 4. Side effects.

\begin{tabular}{|c|c|c|c|c|c|}
\hline \multirow[t]{2}{*}{ Side Effects } & \multicolumn{2}{|c|}{$\begin{array}{c}\text { Group I } \\
(\mathbf{n}=\mathbf{3 0})\end{array}$} & \multicolumn{2}{|c|}{$\begin{array}{l}\text { Group II } \\
(\mathbf{n}=\mathbf{3 0})\end{array}$} & \multirow[t]{2}{*}{$P$-value } \\
\hline & No. & $\%$ & No. & $\%$ & \\
\hline Nausea & 3 & 10.0 & 7 & 23.3 & 0.17 \\
\hline Vomiting & 3 & 10.0 & 5 & 16.7 & 0.70 \\
\hline Headache & 0 & 0.0 & 0 & 0.0 & _- \\
\hline Drowsiness & 0 & 0.0 & 0 & 0.0 & _ \\
\hline Visual Disturbance & 0 & 0.0 & 0 & 0.0 & - \\
\hline Respiratory Depression & 0 & 0.0 & 0 & 0.0 & _ \\
\hline
\end{tabular}

No significant difference regarding postoperative side effects was found between both groups $(P>0.05)$.

concluded that the addition of $\mathrm{MgSO}_{4}$ decreased VAS scores at 4, 6, and 12 hours postoperatively, prolonged the duration of analgesia, and decreased the number of demands for rescue analgesia. They also recommended further studies to establish the efficacy of magnesium in a TAP block.

In our study, we used a dose of $200 \mathrm{mg}(2 \mathrm{~mL}$ of $10 \%$ solution) of magnesium sulfate, and there were no recorded side effects, as it was found that most neu- rological damage associated with the perineural use of magnesium sulfate in the form of vaculation or demyelination was related to a high dose and concentration of the drug (more than 15\% in most reports) $(18,23)$. Several studies included perineural deposition of magnesium sulfate at equal or even higher concentrations without neurological damage or complications (18-20).

We believe that our work is limited by the small sample size, the time gap between the performance of the TAP block, and the first postoperative evaluation of VAS scores after recovery from general anesthesia and also by the lack of the measurement of serum magnesium sulfate level to rule out its systemic effects.

\section{Conclusion}

In conclusion, the addition of $200 \mathrm{mg}$ of magnesium sulfate to bupivacaine in an ultrasound-guided TAP block significantly reduced postoperative opioid requirements, prolonged the duration of analgesia, and reduced the VAS scores in patients who underwent abdominal hysterectomy, without significant side effects.

\section{References}

1. White PF, Kehlet H. Improving postoperative pain management: What are the unresolved issues? Anesthesiology 2010; 112:220-225.

2. Richebé $P$, Beaulieu P. Perioperative pain management in the patient treated with opioids: Continuing professional development. Can J Anaesth 2009; 56:969-981.

3. O'Donnell BD, McDonnell JG, McShane A). The transversus abdominis plane (TAP) block in open retropubic prostatectomy. Reg Anesth Pain Med 2006; 31:91.

4. McDonnell JG, O'Donnell BD, Farrell T, Gough N, Tuite D, Power C, Laffey JG. Transversus abdominis plane block: A cadaveric and radiological evaluation. Reg Anesth Pain Med 2007; 32:399-404.

5. Russon K, Blanco R. Ultrasound-guided transversus abdominal plane block. In: Bigeleisen PE (ed). Ultrasound-Guided Regional Anesthesia and Pain Medicine. Lippincott Williams \& Wilkins Health, Philadelphia 2012, pp 93-96.

6. Rafi AN. Abdominal field block: A new approach via the lumbar triangle. Anaesthesia 2001; 56:1024-1026.

7. Hebbard P. Subcostal transversus abdominis plane block under ultrasound guidance. Anesth Analg 2008; 106:674-675.

8. Niraj G, Kelkar A, Jeyapalan I, Graff-
Baker P, Williams O, Darbar A, Maheshwaran A, Powell R. Comparison of analgesic efficacy of subcostal transversus abdominis plane blocks with epidural analgesia following upper abdominal surgery. Anaesthesia 2011; 66:465-471.

9. Mokini Z. Transverse abdominal plexus block. In: Mokini Z, Vitale G, Costantini A, Fumagalli R (eds). The Flying Publisher Guide to Ultrasound Blocks for the Anterior Abdominal Wall: Principles and Implementation for Adult and Pediatric Surgery. Flying Publisher, Dusseldorf, 2011, pp 35 .

10. Gunduz A, Bilir A, Gulec S. Magnesium added to prilocaine prolongs the dura- 
tion of axillary plexus block. Reg Anesth Pain Med 2006; 31:233-236.

11. Do SH. Magnesium: A versatile drug for anesthesiologists. Korean J Anesthesiol 2013; 65:4-8.

12. Malleeswaran S, Panda N, Mathew P, Bagga R. A randomised study of magnesium sulphate as an adjuvant to intrathecal bupivacaine in patients with mild preeclampsia undergoing caesarean section. Int J Obstet Anesth 2010;19:161-166.

13. Yousef AA, Amr YM. The effect of adding magnesium sulphate to epidural bupivacaine and fentanyl in elective caesarean section using combined spinalepidural anesthesia: A prospective double blind randomised study. Int J Obstet Anesth 2010; 19:401-404.

14. Ghatak T, Chandra G, Malik A, Singh D, Bhatia VK. Evaluation of the effect of magnesium sulphate vs. clonidine as adjunct to epidural bupivacaine. Indian J
Anaesth 2010; 54:308-313.

15. Farouk S. Pre-incisional epidural magnesium provides pre-emptive and preventive analgesia in patients undergoing abdominal hysterectomy. $\mathrm{Br} \mathrm{J}$ Anaesth 2008; 101:694-699.

16. Akutagawa T, Kitahata LM, Saito H, Collins JG, Katz JD. Magnesium enhances local anesthetic nerve block of frog sciatic nerve. Anesth Analg 1984; 63:111-116.

17. Mert T, Gunes Y, Guven M, Gunay I, Ozcengiz D. Effects of calcium and magnesium on peripheral nerve conduction. Pol J Pharmacol 2003; 55:25-30.

18. Lee AR, Yi HW, Chung IS, Ko JS, Ahn HJ, Gwak MS, Choi DH, Choi SJ. Magnesium added to bupivacaine prolongs the duration of analgesia after interscalene nerve block. Can J Anaesth 2012; 59:21-27.

19. Bondok RS, Abd El-Hady AM. Intra-articular magnesium is effective for postoperative analgesia in arthroscopic knee surgery. Br J Anesth 2006; 97:389-392.
20. ElShamaa HA, Ibrahim M, Eldesuky HI. Magnesium sulfate in femoral nerve block, does postoperative analgesia differ? A comparative study. Egy J Anesth 2014; 30:169-173.

21. Kashefi P, Montazeri K, Honarmand A, Masoomi G. Adding magnesium sulphate to lidocaine for intravenous regional anesthesia. Reg Anesth Pain Med 2008; 33:97.

22. Rana S, Verma RK, Singh J, Chaudhary SK, and Chandel A. Magnesium sulphate as an adjuvant to bupivacaine in ultrasound-guided transversus abdominis plane block in patients scheduled for total abdominal hysterectomy under subarachnoid block. Indian J Anaesth 2016; 60:174-179.

23. Ozdogan L, Sastim H, Ornek D, Postaci A, Ayerden T, Dikmen B. Neurotoxic effects of intrathecal magnesium sulphate. Braz J Anesthesiol 2013; 63:139-143. 
